\title{
Neoadjuvant Chemotherapy for Locally Advanced Gastric Cancer: Where we Stand; An Italian Single Center Perspective
}

\author{
ELISABETTA MARINO, LUIGINA GRAZIOSI and ANNIBALE DONINI \\ General and Emergency Surgery, University of Perugia, Perugia, Italy
}

\begin{abstract}
Background/Aim: Neoadjuvant or perioperative chemotherapy is the standard treatment for locally advanced gastric cancer. However, in Eastern countries this is still debated. The aim of our study was to evaluate the survival impact of neoadjuvant chemotherapy. Patients and Methods: A total of 60 patients who underwent preoperative chemotherapy were compared to patients with locally advanced gastric cancer that underwent upfront surgery. Results: Median survival of the entire group curatively treated was 41 months with a median progression-free survival of 38 months. By excluding patients with stage IV disease from the neoadjuvant group, a statistically significant difference was reached both in terms of overall survival and disease-free survival. By subdividing patients according to pTNM stages, neoadjuvant patients showed better survival in stage I and II. Conclusion: Neoadjuvant chemotherapy could be an effective treatment for locally advanced disease. However, randomized studies are still needed to fully understand its role and identify patients that will benefit from it.
\end{abstract}

Treatment of gastric cancer (GC) remains a great challenge for medical and surgical oncologists. Despite the progress made with the introduction of new drugs, overall survival (OS) remains low, especially for advanced cases; furthermore, in Western countries, early diagnosis is also a challenge. Five-year OS of patients affected by stage II and III gastric cancer that undergo curative resection remains very poor, approximately $30 \%(1,2)$.

This article is freely accessible online.

Correspondence to: Elisabetta Marino, General and Emergency Surgery, University of Perugia, Via Dottori 1, 06100, Perugia, Italy. Tel: +39 0755783258, Fax: +39 0755786445, e-mail: elisabetta.marino1986@gmail.com

Key Words: Gastric cancer, neoadjuvant chemotherapy, locally advanced, lymphadenectomy.
To date neoadjuvant or perioperative chemotherapy (NACT) has gained popularity and is considered a standard treatment for locally advanced GC. In addition, it has been introduced in the main Western oncological guidelines associated with a D2 lymph node dissection.

The randomized trials focusing on this matter are somehow old and have been criticized both in terms of inclusion criteria, due to the presence of gastro esophageal junction's tumors, and also for the surgical technique concerning the lymphadenectomy extension. However, both the MAGIC (3) and the FNCLCC-FFCD (4) trials showed an improved prognosis with a gain in the OS of the group of patients receiving multimodal treatment.

Al-Batran et al. (5) demonstrated, in a more recent study, that changing the chemotherapy scheme (FLOT4 vs. ECF/ECX) improved survival; however, also in this work, junctional tumors were included, bringing doubts on the final conclusions.

A meta-analysis by Kumagai (6) et al. on neoadjuvant treatment of resectable esophageal and gastro esophageal junction (GEJ) adenocarcinoma reinforced the concept of a survival benefit provided by NACT. However, the EORTC trial 40954 (7) contrasted previous studies and could not confirm the positive effect (8).

For these reasons, there is still a vivid debate regarding NACT for the treatment of locally advanced GC, with those in favor arguing the positive effect on survival and the opponents arguing that a good surgery performed with a correct lymphadenectomy could overcome the promising results of chemotherapy (9).

The aim of our study was to retrospectively evaluate the survival impact of NACT in patients that underwent gastric resection for adenocarcinoma of the stomach, compared to patients that underwent a curatively upfront gastric surgery. Patients affected by GEJ tumors were excluded.

\section{Patients and Methods}

Patients that underwent a surgery for GC from January 2007 to Dec 2019 in our department were retrospectively reviewed. Exclusion 
criteria were tumors other than adenocarcinoma and patients who could not be candidates for surgery. All the clinical pathological and technical details were retrieved from a prospectively collected database, together with preoperative and postoperative records. We firstly subdivided our series in patients that underwent upfront surgery and those who were treated with chemotherapy prior to surgery. Preoperative blood exams performed within one week before surgery were retrieved. NACT, administered for locally advanced GC with no distant metastasis, included either docetaxel plus oxaliplatin and xeloda (DOX) or with epirubicin, cisplatin and 5-fluorouracil (ECF). General conditions, comorbidities, tumor spread and curative therapeutic options of all the patients were evaluated by medical oncologists, surgeons and radiologists during a weekly held multidisciplinary meeting. The surgical approach consisted of total or subtotal gastrectomy plus a D2/D3 lymphadenectomy. Only in a few selected cases an extended lymphadenectomy was performed. Always the same two expert surgeons performed the surgical approach. Complications' rate was evaluated and reported according to Clavien-Dindo (10) classification. Response to NACT in the pathological report was assessed based on tumor regression grade, according to Becker (11). Tumor pathological classification was based on the AJCC/TNM 8th edition (12). Follow up was carried out every 3 months for the first year, every six months for the second year and once a year thereafter. Complete blood test, including tumor markers, and a total body CT with contrast enhancement were performed; upper endoscopy was performed every year after the surgery.

Recurrence locations were subdivided into local recurrence when the anastomosis was involved, peritoneal recurrence, lymphatic recurrence and hematological (distant) recurrences. If patients had more than one location involved, all of them were considered.

The primary endpoint of our study was to retrospectively evaluate the survival impact of NACT in our cohort of patients on OS and disease-free survival (DFS) compared to patients that underwent upfront surgery; secondarily, also the recurrence patterns were evaluated in the two subgroups.

Statistical analysis. Pearson's $\chi^{2}$ test or Fisher's exact test were used to compare categorical variables, and Student's $t$-test was used to compare continuous variables if normality test was passed, if not Mann-Whitney test was performed. The median follow-up was calculated as the median follow-up of survivors. OS was calculated from the date of gastrectomy in the upfront group and from the beginning of NACT in the pretreated group. Disease free survival was calculated from the date of surgery to the recurrence date in both groups. Survival curves were estimated by the Kaplan-Meier method and compared with a log-rank test. Cox analysis was adopted to identify variables associated with OS and disease-free survival. All significant variables (with $p<0.05$ ) were included in a subsequent Cox multivariable analysis. Statistical analysis was conducted using IBM SPSS Statistics for Windows, Version 23.0. (IBM Corp. Armonk, NY, USA) and GraphPad Prism version 7.2 for Mac, GraphPad Software (San Diego, CA, USA). Statistical significance was set at $p<0.05$.

\section{Results}

A total of 458 patients were admitted in our ward from January 2006 to March 2020 with the diagnosis of gastric tumor. The strategy of patient enrolled is shown in the flow chart in Figure 1.
Thirty-three patients affected by a neoplasia other than adenocarcinoma were excluded; five patients were excluded because were not candidates for surgery due to the general conditions and tumor spread; seventy-four patients treated before 2007 or during 2020 were excluded in order to have at least 6 months of follow up and also because neoadjuvant treatments in our department started in 2007. Based on this selection strategy, we identified 60 patients suitable for preoperative treatment and 287 patient candidates for upfront surgery.

In the preoperative group, one patient was excluded because he underwent also preoperative radiotherapy. Furthermore, 12 patients were excluded because they underwent chemotherapy for the presence of metastatic disease at the diagnosis (conversion therapy). Therefore, 47 patients were included in the study and one of them was not subjected to surgery due to tumor progression during chemotherapy.

In the upfront surgical group, 58 patients were excluded because they were stage 0 or IA; 90 patients were excluded because they were stage IV, and 8 patients were excluded because they were treated with a palliative intent. Therefore 131 patients with locally advanced gastric cancer treated with upfront surgery were compared to 46 patients with locally advanced GC that underwent NACT associated with curative surgery.

Mean age of the entire population was $73.3 \pm 10.4$ and $60.7 \%$ were male. Median OS was 41 months with a median progression-free survival (PFS) of 48 months (Figure 2A and B). Median follow up period was 50 months with a range of 13-162 months. Clinical and surgical characteristics of patients subdivided into the two groups are shown in Table I.

The average age of patients treated with NACT was statistically significantly lower than that of patients that underwent upfront surgery (65.6 vs. 76.1 years old). Female to male ratio was $29 / 18 v s$. $79 / 52$, respectively, and there was no difference between the two groups.

The clinical Tumor involvement (cT) evaluation did not differ between the groups, but there were statistically significantly more patients with clinically positive lymph nodes $(\mathrm{cN}+)$ in the neoadjuvant group $(87.2 \%$ vs. $56.5 \%$, $p=0.0004)$.

Regarding the surgical technique: $61 \%$ of patients treated with NACT underwent a total gastrectomy and $39 \%$ underwent a subtotal procedure; in the upfront surgery group, total gastrectomy was performed only in $23 \%$ of patients. The difference between the two groups was statistically significant with a $p<0.0001$.

In the neoadjuvant group, lymphadenectomy was more extensive; a D2 or plus lymphadenectomy was performed in $50 \%$ and $45.5 \%$ of patients, respectively. Furthermore, in the upfront surgery group, a D1 lymphadenectomy was performed in $25.1 \%$ of cases whereas a D2 and D3 dissection was performed in $58.8 \%$ and $16.1 \%$ of patients, respectively. The difference was statistically significant $(p=0.0002)$. 


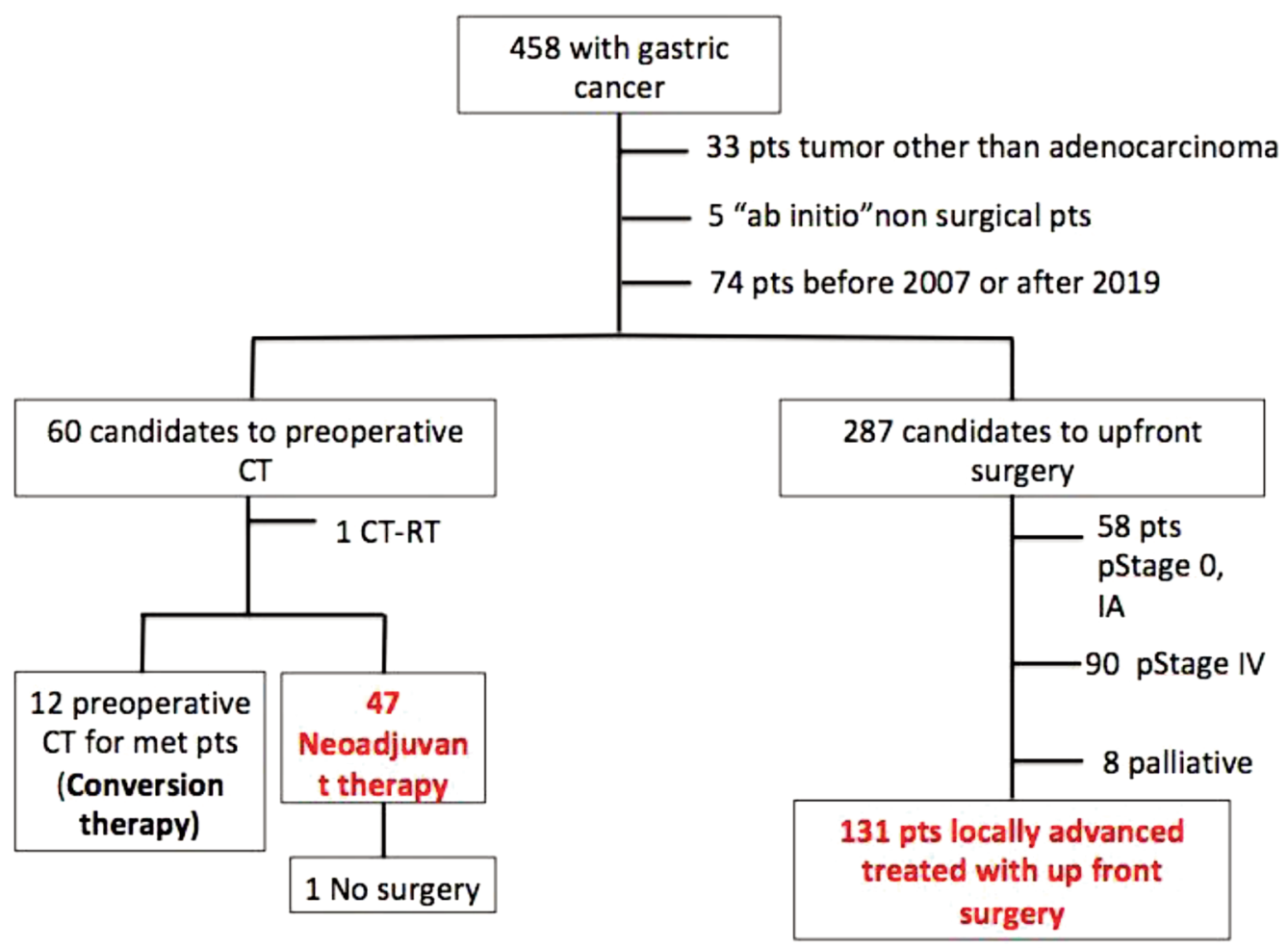

Figure 1. Flow chart of patients enrolled in the study.
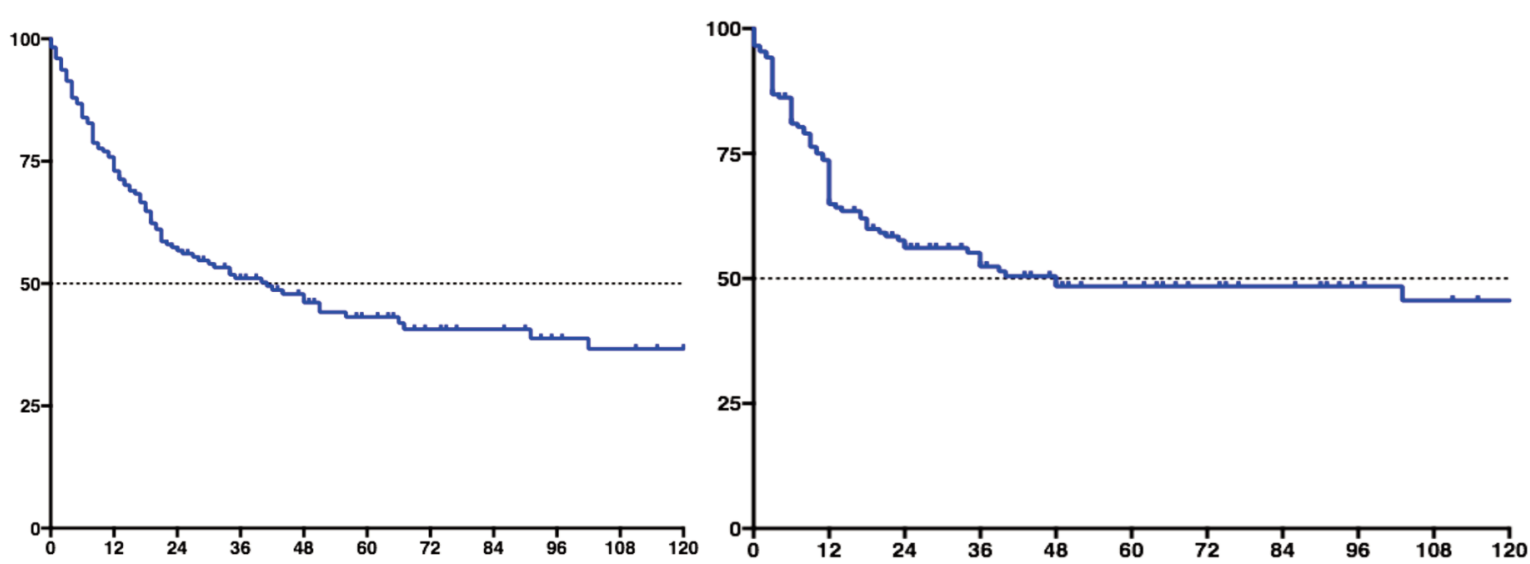

Figure 2. Overall survival (OS) and progression-free survival (PFS) of the entire series; Median OS is 41 months; Median PFS is 48 months.

Comparing OS of the two groups, a median survival of 50 months was observed in the treated group and a median survival of 35 months was observed in the control group (Figure 3A); however, a statistically significant difference was not reached. Also, PFS was not found to be different between the two groups evaluated (Figure 3B).
Pathological and postoperative features of patients enrolled in the study and subdivided according to treatment done are shown in Table II.

No statistical differences were found in terms of Lauren subtype, pathological $\mathrm{T}$ and $\mathrm{N}$, lympho-vascular and perineural invasion, and the number of harvested lymph nodes. The only 
in vivo $35: 3459-3466(2021)$

Table I. Clinical and surgical features of patients enrolled in the study.

\begin{tabular}{|c|c|c|c|}
\hline Clinical and surgical features & NAC & No NAC & $p$-Value \\
\hline Age & $65.6 \pm 9.8$ & $76.13 \pm 9.8$ & $<0.0001$ \\
\hline \multicolumn{4}{|l|}{ Gender } \\
\hline M & (29) $62 \%$ & (79) $60 \%$ & \multirow[t]{2}{*}{ n.s. } \\
\hline $\mathrm{F}$ & (18) $38 \%$ & (52) $40 \%$ & \\
\hline \multicolumn{4}{|l|}{ Karnofsky score } \\
\hline 100 & (33) $70.2 \%$ & (42) $32.1 \%$ & \multirow{6}{*}{0.0002} \\
\hline 90 & (11) $23.4 \%$ & (47) $35.9 \&$ & \\
\hline 80 & (3) $6.4 \%$ & (29) $22.1 \%$ & \\
\hline 70 & 0 & (9) $6.9 \%$ & \\
\hline 60 & 0 & (3) $2.3 \%$ & \\
\hline 50 & 0 & (1) $0.7 \%$ & \\
\hline \multicolumn{4}{|l|}{$\mathrm{cT}^{*}$} \\
\hline $\mathrm{T} 1$ & 0 & 0 & \\
\hline $\mathrm{T} 2$ & (4) $8.5 \%$ & (15) $11.4 \%$ & \multirow[t]{3}{*}{ n.s. } \\
\hline T3 & (27) $57.4 \%$ & (69) $52.7 \%$ & \\
\hline $\mathrm{T} 4$ & (16) $34.1 \%$ & (30) $22.9 \%$ & \\
\hline \multicolumn{4}{|l|}{$\mathrm{cN}$} \\
\hline No & (6) $12.8 \%$ & (56) $42.7 \%$ & \multirow[t]{3}{*}{0.0004} \\
\hline $\mathrm{N}+$ & (41) $87.2 \%$ & (74) $56.5 \%$ & \\
\hline $\mathrm{Nx}$ & 0 & (1) $0.8 \%$ & \\
\hline \multicolumn{4}{|l|}{ Surgery type } \\
\hline Total & (28) $61 \%$ & (30) $23 \%$ & \multirow[t]{2}{*}{$<0.0001$} \\
\hline Subtotal & (18) $39 \%$ & (101) $77 \%$ & \\
\hline \multicolumn{4}{|l|}{ Lymphadenectomy } \\
\hline D1 & (3) $6.5 \%$ & (33) $25.1 \%$ & \multirow[t]{3}{*}{0.0002} \\
\hline D2 & (23) $50 \%$ & (77) $58.8 \%$ & \\
\hline D2 plus & (20) $43.5 \%$ & (21) $16.1 \%$ & \\
\hline
\end{tabular}

NAC: Neoadjuvant chemotherapy. Bold $p$-Values indicate statistical significance.

statistically significant difference was in terms of pathological stages. Pathological stage IV was present only in the neoadjuvant group and not in the upfront surgery one.

For this reason, we analyzed the survival curves, excluding stage IV from the neoadjuvant group as shown in Figure 4, and a statistically significant difference was achieved, both for OS and PFS ( $p=0.02)$.

However, subdividing patients according to different pathological stages, a statistically significant difference was found only in stage I and II, but not in stage III ( $p=0.02$ and $p=0.06$ ).

By analyzing patients according to histological subtype, a statistically significant difference in survival in the intestinal type was found; patients who underwent NACT showed a better OS when compared to those who were treated upfront with surgery; this difference was not found in the diffuse subgroup (Figure 5). Complication rates did not differ between the two groups.

In terms of recurrence rate, the two populations did not differ significantly. Recurrences occurred in $30.3 \%$ of the neoadjuvant population and in $40.5 \%$ of the up-front surgical group. Also, locations of recurrence were similar (Table III).
Table II. Pathological features of patients enrolled in the study.

\begin{tabular}{|c|c|c|c|}
\hline $\begin{array}{l}\text { Post operative and } \\
\text { pathological features }\end{array}$ & NAC & No NAC & $p$-Value \\
\hline \multicolumn{4}{|l|}{ Lauren histotype } \\
\hline Intestinal & (25) $53.2 \%$ & (74) $56.5 \%$ & \\
\hline Diffuse & (17) $36.2 \%$ & (37) $28.2 \%$ & n.s. \\
\hline Signet ring cell & (9) $19.1 \%$ & (17) $13 \%$ & \\
\hline Mixed & (5) $10.6 \%$ & (20) $15.3 \%$ & \\
\hline Veno-lymphatic invasion & & & n.s. \\
\hline Yes & (21) $44.7 \%$ & (67) $51.1 \%$ & \\
\hline No & (5) $10.6 \%$ & (15) $11.5 \%$ & \\
\hline Missing & (20) $42.5 \%$ & (49) $37.4 \%$ & \\
\hline Perineural invasion & & & n.s. \\
\hline Yes & (19) $40.2 \%$ & (55) $42 \%$ & \\
\hline No & (7) $14.9 \%$ & (26) $19.8 \%$ & \\
\hline Missing & (20) $42.5 \%$ & (50) $38.2 \%$ & \\
\hline \multicolumn{4}{|l|}{$\mathrm{pT}$} \\
\hline 1 & (3) $6.4 \%$ & (4) $3.1 \%$ & \\
\hline 2 & (8) $17.0 \%$ & (27) $20.6 \%$ & \\
\hline 3 & (14) $29.8 \%$ & (52) $39.7 \%$ & n.s. \\
\hline $4 a$ & (12) $25.5 \%$ & (39) $29.8 \%$ & \\
\hline $4 \mathrm{~b}$ & (4) $8.5 \%$ & (9) $6.8 \%$ & \\
\hline \multicolumn{4}{|l|}{$\mathrm{pN}$} \\
\hline 0 & (16) $34.0 \%$ & (33) $25.2 \%$ & \\
\hline 1 & (11) $23.4 \%$ & (24) $18.3 \%$ & \\
\hline 2 & (8) $17.0 \%$ & (29) $22.1 \%$ & n.s. \\
\hline $3 a$ & (7) $14.9 \%$ & (23) $17.6 \%$ & \\
\hline $3 b$ & (4) $8.5 \%$ & (22) $16.8 \%$ & \\
\hline $\mathrm{N}^{\circ}$ of lymphonodes harvested & $36.1 \pm 16.6$ & $31.8 \pm 20.0$ & n.s. \\
\hline \multicolumn{4}{|c|}{ pTNM } \\
\hline I & (7) $15.0 \%$ & (12) $9.2 \%$ & \\
\hline II & (14) $29.8 \%$ & (46) $35.1 \%$ & $<0.0001$ \\
\hline III & (13) $27.6 \%$ & (73) $55.7 \%$ & \\
\hline IV & (13) $27.6 \%$ & 0 & \\
\hline \multicolumn{4}{|l|}{$\begin{array}{l}\text { Clavien-Dindo } \\
\text { complications' rate }\end{array}$} \\
\hline 0 & (21) $44.6 \%$ & (45) $34.3 \%$ & \\
\hline I-II & (16) $34.1 \%$ & (65) $49.6 \%$ & n.s. \\
\hline III-IV & (8) $17 \%$ & (13) $9.9 \%$ & \\
\hline $\mathrm{V}$ & (1) $2.1 \%$ & (8) $6.1 \%$ & \\
\hline
\end{tabular}

NAC: Neoadjuvant chemotherapy.

Even if it seems that in the NAC group there are less recurrences and less hematological and peritoneal recurrences, a statistically significant difference was not reached and, therefore, it is only a trend that needs to be confirmed.

\section{Discussion}

This study evaluated survival outcomes comparing results of a neoadjuvant group to those of a control group that underwent upfront surgery in an Italian population affected by locally advanced GC. In Western countries, survival of patients with locally advanced GC is poor, showing a local recurrence rate as high as $50 \%$ and a long-term survival rate 

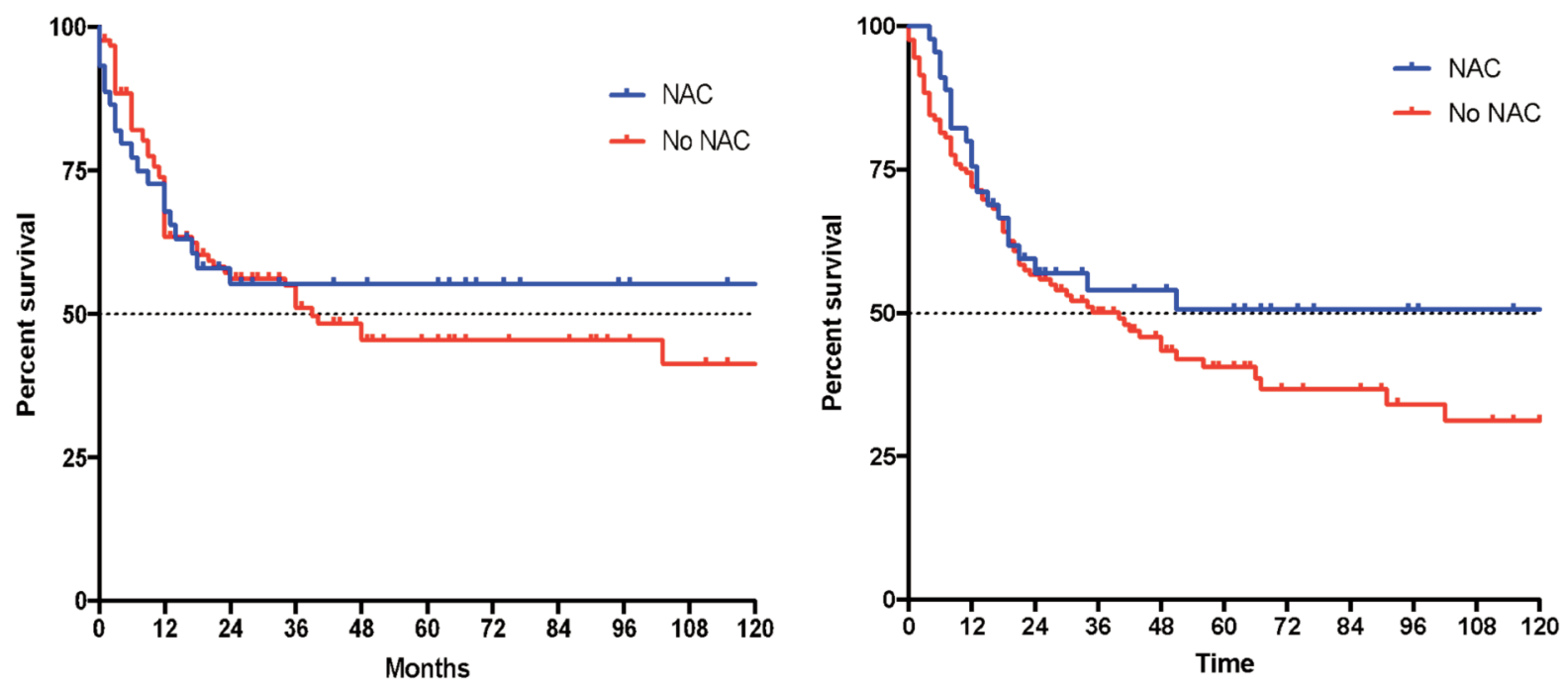

Figure 3. Overall survival and progression-free survival of the two groups; no statistically significant differences were obtained.
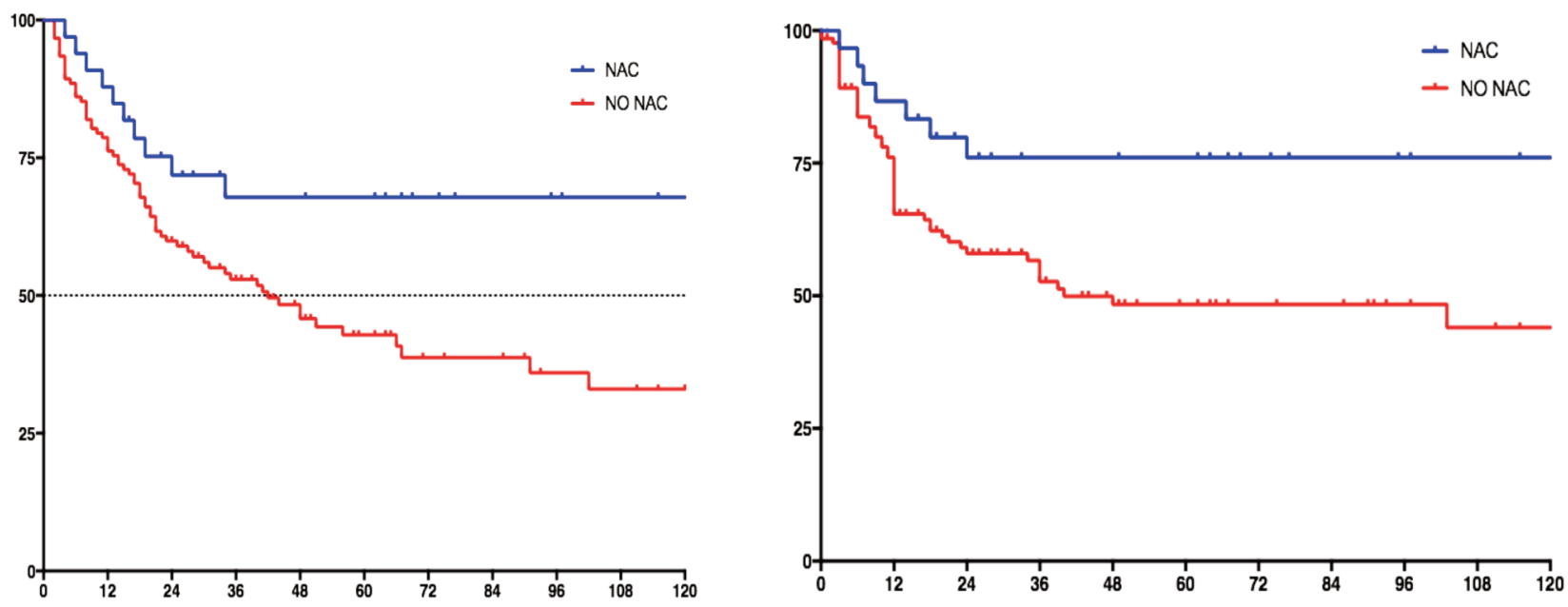

Figure 4. Overall survival and progression-free survival comparison of patients with locally advanced gastric cancer according to treatment; $p<0.05$.

of less than $30 \%$ even if a radical and oncologically curative surgery has been performed (13).

The survival benefit from the NACT treatment remains unclear with the two most important Western trials $(3,4)$ on the topic showing an improvement in survival but had important methodology issues, such as a mixture of tumors with different biological behaviors [esophagus, esophagusgastric junction (EGJ) and stomach] and an inadequate lymphadenectomy (14).

Our results demonstrating significant benefits both in terms of OS and PFS in the NAC group are encouraging. To have a more accurate analysis we excluded patients affected by EGJ tumor and patients that underwent a palliative treatment. Furthermore, two expert surgeons performed the surgery every time, implying a standardized surgical procedure. The difference in terms of OS and PFS were also shown after excluding patients with a pathological stage IV from the neoadjuvant group, and it remained statistically significant especially in earlier stages.

Moreover, it seems that patients with a pathological N0 could also benefit from a preoperative treatment. This may be due to the fact that patients with pathological N0 after 

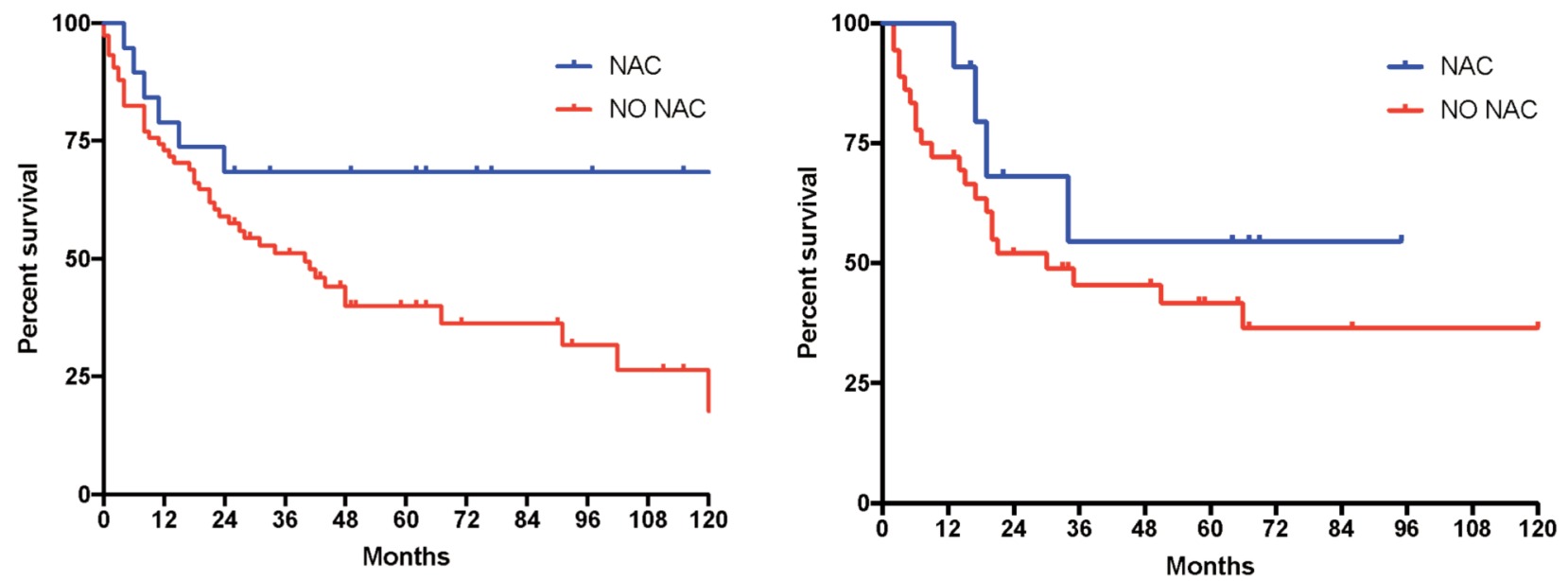

Figure 5. Overall survival comparison in patients with intestinal subtype $(p<0.05)$ and diffuse subtype $(p>0.05)$.

Table III. Recurrence rate and location in the two groups, no statistical difference was shown $(p>0.05)$.

\begin{tabular}{lccc}
\hline & NAC (33) & No NAC (131) & $p$-Value \\
\hline $\begin{array}{l}\text { Recurrence } \\
\text { Y }\end{array}$ & & & \\
N & (10) $30.3 \%$ & (53) $40.5 \%$ & \\
Location & (23) $69.7 \%$ & (78) $59.5 \%$ & N.S. \\
Hem. & & & \\
Local & (2) $6.1 \%$ & (16) $12.2 \%$ & \\
Lymph. & (2) $6.1 \%$ & (7) $5.3 \%$ & \\
Perit. & (4) $12.1 \%$ & (19) $14.5 \%$ & N.S. \\
\hline
\end{tabular}

Hem.: Hematological recurrence; Lymph.: lymph node recurrence; Perit.: peritoneal recurrence.

surgery and NAC treatment, might have become NO after chemotherapy. In fact, during the clinical study there were more $\mathrm{N}+$ in the NAC group compared to the upfront group (87.2\% vs. $56.5 \%, p<0.005)$.

As the tumor regression grade (TRG) system only evaluates the primary tumor, it is unknown whether the assessment of lymph node regression would help predict the outcome; in the literature, there are studies asserting that node status is more important as a prognostic factor than primary tumor regression $(15,16)$, lymph node involvement being one of the most important prognostic factors in gastric cancer patients.

However, in our study, TRG, evaluating the primary tumor response to chemotherapy, correlated with OS. A larger sample is needed in order to clarify which tumour regression scoring system should be adopted in order to have the optimal evaluation of patients' response to NACT.
We also need a more accurate lymph node staging system after chemotherapy to be able to compare results among different centers.

In our series, patients affected by the intestinal subtype had a better survival when they underwent neoadjuvant chemotherapy compared to patients affected by the diffuse type. To date, no randomized trial of neoadjuvant chemotherapy has evaluated the response or survival of patients with different histologic subtypes. Therefore, findings cannot be supported by clinical research results. However, a recent study by Zurlo et al. (17) yielded results similar to ours; but they have also stated that in the present genomic era, a histology-driven approach to crucial decisions seems simplistic and rather obsolete. Probably patients with the intestinal type could be considered more responsive due to the more differentiated behavior of tumoral cells.

The most frequently used chemotherapy schema is the combination of docetaxel, oxaliplatin, and xeloda (DOX). Initially, our oncologist adopted the drug combination of Epirubicin/ Cisplatin/5-Fluorouracil (ECF). We are aware that these results will not be comparable to the nowadays standard treatment established by the FLOT-4 trial (5). Concerning the safety and complication rate, although NACT for gastric cancer is widely accepted and practiced, few studies have investigated the surgical morbidity of this strategy (7, 18-20). Morbidity and mortality in our two groups did not differ significantly, but mortality was lower in the NACT group. However, Yoshikawa et al. (21) reported a very high mortality (5\%) in D2 lymphadenectomy after chemotherapy when compared to their previous randomized trials JCOG 9912 (22) and JCOG9502 (23).

In a more recent meta-analysis, van den Ende (24) concluded that pre-operative FLOT only showed a minor 
increase in adverse events compared to pre-operative doublet or triplet regimens. Therefore, pre-operative FLOT should be the preferred regimen in the perioperative setting for fit patients. They also asserted that surgical outcomes are not impaired by pre-operative chemotherapy and can thus be safely administered. For this reason, we are looking forward to more results with this regimen, now adopted widely in Europe. In conclusion, NACT could be considered an effective treatment, however, it has to be associated with an excellent surgery, performed by a surgical expert.

Moreover, patients with the diffuse type do not have a survival benefit from chemotherapy; this difference is probably due to the tumor biology, which needs to be further investigated. In the future, it is possible that the therapeutic strategy will be tailored according to genic and bimolecular variability, evaluated after an endoscopic biopsy.

Our exciting results are negatively affected by some limitations; first the retrospective nature of the study and the use of a different chemotherapy schema. On the other hand, good points in favor of the study are the long follow up time and the strict inclusion criteria, which lead to very homogenous groups.

We hope that, in the future, the neoadjuvant approach is driven by molecular biology tests on gastric biopsies and administered only to patients that could really benefit from a multimodal approach, and patients judged not eligible for NACT will be subjected to an aggressive surgery with a correct extended lymphadenectomy.

\section{Conflicts of Interest}

All the Authors have no conflicts of interest to declare in relation to this study.

\section{Authors' Contributions}

Elisabetta Marino and Luigina Graziosi: Conceptualization, Methodology; Elisabetta Marino: Data curation, Writing- Original draft preparation; Elisabetta Marino, Luigina Graziosi and Annibale Donini: Writing- Reviewing and Editing; Annibale Donini: Supervision.

\section{References}

1 Asplund J, Kauppila JH, Mattsson F and Lagergren J: Survival trends in gastric adenocarcinoma: A population-based study in Sweden. Ann Surg Oncol 25(9): 2693-2702, 2018. PMID: 29987609. DOI: 10.1245/s10434-018-6627-y

2 Statistics adapted from the American Cancer Society's (ACS) publication, Cancer Facts \& Figures 2020, and the ACS website. Available at: https://www.cancer.org/research/cancer-factsstatistics/all-cancer-facts-figures/cancer-facts-figures-2020.html [Last accessed on September 17, 2021]

3 Cunningham D, Allum WH, Stenning SP, Thompson JN, Van de Velde CJ, Nicolson M, Scarffe JH, Lofts FJ, Falk SJ, Iveson TJ, Smith DB, Langley RE, Verma M, Weeden S, Chua YJ and MAGIC Trial Participants: Perioperative chemotherapy versus surgery alone for resectable gastroesophageal cancer. N Engl J Med 355(1): 11-20, 2006. PMID: 16822992. DOI: 10.1056/NEJMoa 055531

4 Ychou M, Boige V, Pignon JP, Conroy T, Bouché O, Lebreton G, Ducourtieux M, Bedenne L, Fabre JM, Saint-Aubert B, Genève J, Lasser P and Rougier P: Perioperative chemotherapy compared with surgery alone for resectable gastroesophageal adenocarcinoma: an FNCLCC and FFCD multicenter phase III trial. J Clin Oncol 29(13): 1715-1721, 2011. PMID: 21444866. DOI: $10.1200 / J C O .2010 .33 .0597$

5 Al-Batran SE, Homann N, Pauligk C, Goetze TO, Meiler J, Kasper S, Kopp HG, Mayer F, Haag GM, Luley K, Lindig U, Schmiegel W, Pohl M, Stoehlmacher J, Folprecht G, Probst S, Prasnikar N, Fischbach W, Mahlberg R, Trojan J, Koenigsmann $\mathrm{M}$, Martens UM, Thuss-Patience $\mathrm{P}$, Egger M, Block A, Heinemann V, Illerhaus G, Moehler M, Schenk M, Kullmann F, Behringer DM, Heike M, Pink D, Teschendorf C, Löhr C, Bernhard H, Schuch G, Rethwisch V, von Weikersthal LF, Hartmann JT, Kneba M, Daum S, Schulmann K, Weniger J, Belle S, Gaiser T, Oduncu FS, Güntner M, Hozaeel W, Reichart A, Jäger E, Kraus T, Mönig S, Bechstein WO, Schuler M, Schmalenberg H, Hofheinz RD and FLOT4-AIO Investigators: Perioperative chemotherapy with fluorouracil plus leucovorin, oxaliplatin, and docetaxel versus fluorouracil or capecitabine plus cisplatin and epirubicin for locally advanced, resectable gastric or gastro-oesophageal junction adenocarcinoma (FLOT4): a randomised, phase 2/3 trial. Lancet 393(10184): 1948-1957, 2019. PMID: 30982686. DOI: 10.1016/S01406736(18)32557-1

6 Kumagai K, Rouvelas I, Tsai JA, Mariosa D, Klevebro F, Lindblad M, Ye W, Lundell L and Nilsson M: Meta-analysis of postoperative morbidity and perioperative mortality in patients receiving neoadjuvant chemotherapy or chemoradiotherapy for resectable oesophageal and gastro-oesophageal junctional cancers. Br J Surg 101(4): 321-338, 2014. PMID: 24493117. DOI: $10.1002 /$ bjs. 9418

7 Schuhmacher C, Gretschel S, Lordick F, Reichardt P, Hohenberger W, Eisenberger CF, Haag C, Mauer ME, Hasan B, Welch J, Ott K, Hoelscher A, Schneider PM, Bechstein W, Wilke H, Lutz MP, Nordlinger B, Van Cutsem E, Siewert JR and Schlag PM: Neoadjuvant chemotherapy compared with surgery alone for locally advanced cancer of the stomach and cardia: European Organisation for Research and Treatment of Cancer randomized trial 40954. J Clin Oncol 28(35): 5210-5218, 2010. PMID: 21060024. DOI: 10.1200/JCO.2009.26.6114

8 Ganschow P, Hofmann L, Stintzing S, Heinemann V, Angele M, Werner J and Schulz C: Operative results and perioperative morbidity after intensified neoadjuvant chemotherapy with FLOT for gastroesophageal adenocarcinoma impact of intensified neoadjuvant treatment. J Gastrointest Surg 25(1): 58-66, 2021. PMID: 32040809. DOI: 10.1007/s11605-01904511-7

9 Mihmanli M, Ilhan E, Idiz UO, Alemdar A and Demir U: Recent developments and innovations in gastric cancer. World $\mathrm{J}$ Gastroenterol 22(17): 4307-4320, 2016. PMID: 27158199. DOI: 10.3748/wjg.v22.i17.4307

10 Dindo D, Demartines N and Clavien PA: Classification of surgical complications: a new proposal with evaluation in a cohort of 6336 patients and results of a survey. Ann Surg 240(2): 205-213, 2004. PMID: 15273542. DOI: 10.1097/01.sla.0000133083.54934.ae 
11 Becker K, Mueller JD, Schulmacher C, Ott K, Fink U, Busch R, Böttcher K, Siewert JR and Höfler H: Histomorphology and grading of regression in gastric carcinoma treated with neoadjuvant chemotherapy. Cancer 98(7): 1521-1530, 2003. PMID: 14508841. DOI: $10.1002 / \mathrm{cncr} .11660$

12 Amin MB, Edge S, Greene F, Byrd DR, Brookland RK, Washington MK, Gershenwald JE, Compton CC, Hess KR, Sullivan DC, Jessup JM, Brierley JD, Gaspar LE, Schilsky RL, Balch CM, Winchester DP, Asare EA, Madera M, Gress DM and Meyer LR (eds.): AJCC Cancer Staging Manual (8th edition). Springer International Publishing, American Joint Commission on Cancer, 2017.

$13 \mathrm{Hu}$ SB, Liu CH, Wang X, Dong YW, Zhao L, Liu HF, Cao Y, Zhong DR, Liu W, Li YL, Gao WS, Bai CM, Shang ZH and Li $X Y$ : Pathological evaluation of neoadjuvant chemotherapy in advanced gastric cancer. World J Surg Oncol 17(1): 3, 2019. PMID: 30606195. DOI: 10.1186/s12957-018-1534-z

14 Charruf AZ, Ramos MFKP, Pereira MA, Dias AR, de Castria TB, Zilberstein B, Cecconelo I and Ribeiro U: Impact of neoadjuvant chemotherapy on surgical and pathological results of gastric cancer patients: A case-control study. J Surg Oncol 121(5): 833-839, 2020. PMID: 31943232. DOI: 10.1002/jso.25839

15 Pereira MA, Ramos MFKP, Dias AR, Cardili L, Ribeiro RRE, Charruf AZ, de Castria TB, Zilberstein B, Ceconello I, Avancini Ferreira Alves V, Ribeiro U Jr and de Mello ES: Lymph node regression after neoadjuvant chemotherapy: A predictor of survival in gastric cancer. J Surg Oncol 121(5): 795-803, 2020. PMID: 31773740 . DOI: 10.1002/jso.25785

16 Fujitani K, Mano M, Hirao M, Kodama Y and Tsujinaka T: Posttherapy nodal status, not graded histologic response, predicts survival after neoadjuvant chemotherapy for advanced gastric cancer. Ann Surg Oncol 19(6): 1936-1943, 2012. PMID: 22187120. DOI: 10.1245/s10434-011-2165-6

17 Zurlo IV, Basso M, Strippoli A, Calegari MA, Orlandi A, Cassano A, Di Salvatore M, Garufi G, Bria E, Tortora G, Barone $\mathrm{C}$ and Pozzo C: Treatment of locally advanced gastric cancer (LAGC): Back to Lauren's classification in pan-cancer analysis era? Cancers (Basel) 12(7): 1749, 2020. PMID: 32630186. DOI: 10.3390/cancers12071749

18 Fujitani K, Ajani JA, Crane CH, Feig BW, Pisters PW, Janjan N, Walsh GL, Swisher SG, Vaporciyan AA, Rice D, Welch A, Baker J, Faust $\mathrm{J}$ and Mansfield PF: Impact of induction chemotherapy and preoperative chemoradiotherapy on operative morbidity and mortality in patients with locoregional adenocarcinoma of the stomach or gastroesophageal junction. Ann Surg Oncol 14(7): 2010-2017, 2007. PMID: 17342569. DOI: $10.1245 / \mathrm{s} 10434-006-9198-2$
19 Valenti V, Hernandez-Lizoaín JL, Beorlegui MC, Diaz-Gozalez JA, Regueira FM, Rodriguez JJ, Viudez A, Sola I and Cienfuegos JA: Morbidity, mortality, and pathological response in patients with gastric cancer preoperatively treated with chemotherapy or chemoradiotherapy. J Surg Oncol 104(2): 124129, 2011. PMID: 21509785. DOI: 10.1002/jso.21947

$20 \mathrm{Wu}$ L, Ge L, Qin Y, Huang M, Chen J, Yang Y and Zhong J: Postoperative morbidity and mortality after neoadjuvant chemotherapy versus upfront surgery for locally advanced gastric cancer: a propensity score matching analysis. Cancer Manag Res 11: 6011-6018, 2019. PMID: 31308742. DOI: 10.2147/CMAR.S203880

21 Yoshikawa T, Sasako M, Yamamoto S, Sano T, Imamura H, Fujitani K, Oshita H, Ito S, Kawashima Y and Fukushima N: Phase II study of neoadjuvant chemotherapy and extended surgery for locally advanced gastric cancer. Br J Surg 96(9): 1015-1022, 2009. PMID: 19644974. DOI: 10.1002/bjs.6665

22 Boku N, Yamamoto S, Shirao K, Doi T, Sawaki A, Koizumi W, Saito H, Yamaguchi K, Kimura A and Ohtsu A: Randomized phase III study of 5-fluorouracil (5-FU) alone versus combination of irinotecan and cisplatin $(\mathrm{CP})$ versus $\mathrm{S}-1$ alone in advanced gastric cancer (JCOG9912). J Clin Oncol 25(18_suppl): LBA4513-LBA4513, 2007.

23 Kurokawa Y, Sasako M, Sano T, Yoshikawa T, Iwasaki Y, Nashimoto A, Ito S, Kurita A, Mizusawa J, Nakamura K and Japan Clinical Oncology Group (JCOG9502): Ten-year followup results of a randomized clinical trial comparing left thoracoabdominal and abdominal transhiatal approaches to total gastrectomy for adenocarcinoma of the oesophagogastric junction or gastric cardia. Br J Surg 102(4): 341-348, 2015. PMID: 25605628. DOI: 10.1002/bjs. 9764

24 van den Ende T, Abe Nijenhuis FA, van den Boorn HG, Ter Veer E, Hulshof MCCM, Gisbertz SS, van Oijen MGH and van Laarhoven HWM: COMplot, a graphical presentation of complication profiles and adverse effects for the curative treatment of gastric cancer: a systematic review and metaanalysis. Front Oncol 9: 684, 2019. PMID: 31403035. DOI: 10.3389/fonc. 2019.00684
Received August 24, 2021

Revised September 17, 2021

Accepted September 23, 2021 